\title{
The Pattern of Proof of Integrity for Applications on Blockchain Platform
}

\author{
Monirah D. Almalki and Kawther Saeedi \\ Information Systems Department, Department of Computer Science, Faculty of Computing and \\ Information Technology, King Abdulaziz University, Jeddah, Saudi Arabia \\ malmalki0408@stu.kau.edu.sa
}

\begin{abstract}
Blockchain is a new technology that has been taking much attention in many industries. Many studies highlighted that the difficulty of understanding Blockchain is a challenge to implement it in business. As a result, conducting studies in the design of Blockchain applications is essential to simplify understand its impact on the integrity, efficiency, and productivity of transactions. Accordingly, this research studied the role of Blockchain in achieving integrity for high-value records such as agreements and contracts. In software engineering, creating patterns help to understand the problem that occurs over and over again and provide a solution to it. Hence, the motivation of this research is to contribute to the area of design pattern approach for Blockchain applications. We explored the blockchain ability to solve the lack of integrity. Then, we represented the solution as a pattern called proof of integrity (PoI). Next, we built an application to verify the certificates authentication practically and check how the built application compatible with PoI pattern. We concluded, PoI pattern could be used as a model to solve the problem of authentication in many industries and as a guide to help organizations moving efficiently to the blockchain.
\end{abstract}

Keywords: Blockchain (BC), Pattern, Integrity, Authentication, Proof of Integrity (PoI).

\section{Introduction}

Blockchain technology is a ledger that effectively records the flow of assets in or out of an organization, and it is updated every time a transaction occurs. Blockchain can provide several improvements to business-like integrity, efficiency, productivity, time and cost reduction. It relies on decentralized databases that provide integrity, collaborative, transparent, verifiable, and auditable records for all transactions.

One of the challenges in the business today is achieving the integrity of the records $[1,2]$. Accordingly, this paper will discuss the main research question; What the role of Blockchain technology to achieve data integrity? We divided this main research question into the following two sub-questions: Does the e-business pattern will help to explain the role of $\mathrm{BC}$ in integrity? How can we evaluate the created pattern? We will create a pattern to simplify understanding the role of Blockchain in enhancing integrity in applications. To answer the research questions; different resources such as academic articles, conferences papers, books and white papers of Blockchain Technologies will help us in answering.

Consequently, the contribution of this research is twofold: Firstly, creating a pattern to show the role of BC in business. Second, build a blockchain application to evaluate the pattern. This paper covers the following 
sections: blockchain overview, problem statement, solution, followed by the material and methods, the evaluation part - finally, the conclusion.

\section{Blockchain Overview}

\section{A. Blockchain Definition}

The Blockchain technology is a distributed ledger that provides a decentralized and continuously growing immutable record of transactions [3]. It stores all processed transactions in chronological order to make a set of blocks that contain the history of all previous transactions ${ }^{[4]}$. Each block in the blockchain contains a hash value of the preceding block and information on transaction records included in the relevant block ${ }^{[5]}$. Block is a data structure containing transaction data ${ }^{[6]}$.

\section{B. Reviews Articles}

The process of saving records on blockchain depends on the concept of hash. Hash "is a one-way function that takes data of any size as input and produces a fixed length output." Any change in the input should propagate through the entire output so that outputs for similar input have no predictable similarity ${ }^{[7]}$. A Private blockchain concept is used to allow business to adopt blockchain technology. Blockchain systems in business environments are called private (or permission) when the user should have the authority to participate in this blockchain network. As opposed to the blockchain systems operating in public (or permissionless) environments where anyone can join and leave. It is "essentially an asset database that can be shared across a peer to peer network of the institution" [2]. Peer-to-Peer is the "transmission Communication occurs directly between peers instead of through a central node like crypto-currency or smart contracts [8]. Smart contracts "are computer programs that autonomously execute the terms of a contract" [9]. The first successful way of implementation Blockchain started with Bitcoin. Bitcoin is a set of transactions that coding data about transferring cryptocurrency. It is a ledger that keeps track of all transferring cryptocurrency transactions ${ }^{[10]}$.

\section{Material and Methods}

To achieve research goals, we followed the research methodology created by Peffers et al. ${ }^{[11]}$, it called design science research methodology (DSRM). This methodology depends on the implementing the following steps sequentially as shown in Fig. 1: The first step, Identify the problem; second, determine the solution; third, design and development; fourth, demonstrate, and fifth step, evaluation. We employed this approach because it is a comprehensive approach and it can be used for a wide range of research in the information systems field. In our research, we moved sequentially from the identify problem until the evaluation step as explained in this paper. This methodology supports design science research components and provides a guideline for the researchers to display their outcomes.

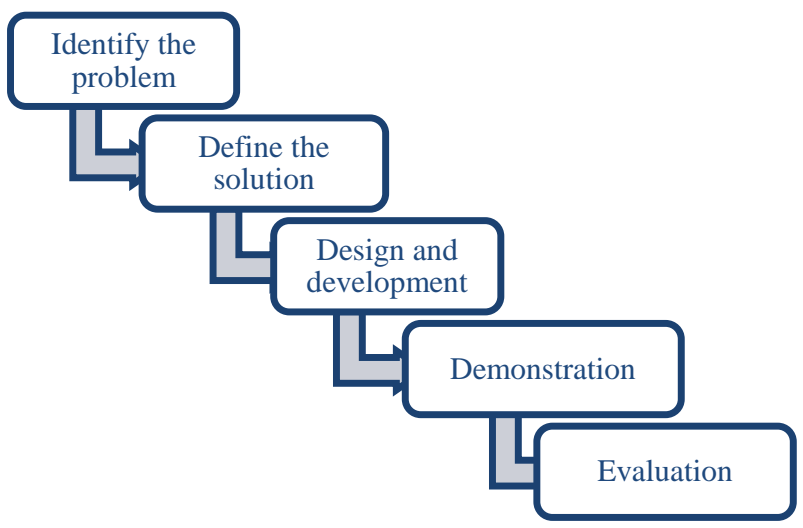

Fig. 1. Design Science Research Methodology (DSRM)

\section{A. Identify the Problem}

Adopting Blockchain in business requires a systematic way to reach the needed goals. Some recent research like the study ${ }^{[4]}$ 
highlighted that one of the important topics that need to be addressed by the research community is finding approaches to simplify implementing blockchain in organizations. According to ${ }^{[12]}$, despite the wide range of $\mathrm{BC}$ researches, still, there is a lack in the design of software applications. Likewise, as stated by ${ }^{[13]},{ }^{[14]}$, one of the implementation challenges of Blockchain in business is the difficulty of understanding. Moreover, Babu et al. [15] mentioned that most of the research on blockchain technology focused only on technical perspectives such as security, cryptography and privacy issues. Whereas the part of integration blockchain in business still needs more research. Additionally, according to a study by Huaiqing et al. ${ }^{[16]}$, they found that the adoption of Blockchain technology in organizations is not at an appropriate level of maturity and there is a need for a means to facilitate and assist with blockchain implementation. Thus, conducting studies is a required step to simplifying adopt Blockchain in business. According to ${ }^{[17]}$, despite the organizations being still unaware of the influences of BC technology on their business, they should be able to know the benefits of this technology. Blockchain may fundamentally help to solve many problems in the business world such as lack of transparency, authentication, and security ${ }^{[18]}$. Therefore, knowing the role of BC technology in solving current problems at business is an important issue which requires to be covered in detail ${ }^{[19]}$. The researches community need to contribute by exploring the role of $\mathrm{BC}$ along with the impact on the business.

One of the challenges in the world of business is achieving the integrity of the records. In this research, we will explain the role of $\mathrm{BC}$ to achieve integrity. Integrity is an essential characteristic in the process of saving records especially the high-value data such as agreements and contracts. Integrity means that a system behaves as intended, and it involves many aspects such as security and correctness, in particular, both architectural concepts have very different approaches to ensure integrity.

\section{B. Define Solution}

In this research, we will explore how BC could be used as a tool to achieve integrity and prove the authentication for high values documents. According to ${ }^{[20]}$, one of the ways to understand technologies such as blockchain is creating patterns. The pattern language is a useful tool to help the stakeholders gain a better understanding of the relationship between business requirements and technical solutions. A process of designing pattern in software engineering helps understands the problem that occurs over and over again and then describes the solution to that problem in such a way that we can use this solution many times over. The pattern in software engineering is high-level constructs used to establish the primary business purpose of any solution ${ }^{[21]}$.

We will create a pattern to explain the role of $\mathrm{BC}$ in achieving integrity; this pattern will help to guide business that wants to achieve integrity in their records. The purpose of choosing a pattern as a solution due to that developing software has many similarities; thus, creating patterns has gained acceptance among software designers and developers. It enables efficiency in both the communication and the implementation of software design based upon a common vocabulary and reference. Moreover, creating a pattern helps to share knowledge with others and to rapidly develop solutions without sacrificing the quality and service expected from those solutions ${ }^{[21]}$.

\section{Design Pattern of Proof of Integrity (PoI)}

Since the blockchain is a challenge to understand especially in the technical aspect and its relation to the business aspect ${ }^{[22]}$; it is 
essential to find an apparent way to recognize it from the aspect of integrity in a variety of industries. The standard framework by Liping Zhao et al. ${ }^{[20]}$ was used in this research to document the patterns of proof of integrity for e-business. This framework provides support for developing software architectures for the ebusiness domain, and it is easy to compare different cases. The framework consists of these sections: Pattern name, context/ the problem, solution, and usage of the pattern.

\section{Pattern Name: Proof of Integrity}

In this part, we will propose a pattern called proof of Integrity (PoI) to describe how $\mathrm{BC}$ can prove the integrity of a record. PoI pattern is commonly observed in the applications that provide users the ability to verify whether a particular document, record, agreement, or contract is authentic. Proving of Integrity can solve many problems in business such as issues of counterfeit, fraud, a problem of proving ownership, authorship, and identity.

\section{Context/ the Problem}

The process of proving the integrity of certain data is a challenge in case the data is scattered across different organizations; each organization keeps its records in different systems. As a result, there is no sharing or integrating between these systems. Also, the formats and standards of the data are varying which makes the process of checking is difficult. Besides, no single source of the truth, thus, the process of checking the integrity may require searching in many databases, systems, or manually in hard copies. This situation suffers from the absence of the complete history of the transaction; as a result, this could lead to delays, additional efforts and costs, and incorrect decision making.

\section{Solution}

Blockchain can solve the issue of proving whether a specific document or agreement is authentic or not. The process occurs by inquiring through Blockchain Platform.

This pattern consists of the following components:

\section{Users/participants}

All the users included in the process include issuer, recipient, and verifier.

- The issuer, the user who creates a new record.

- Recipient, the user who owns the record.

- Verifier, the user who wants to inquire about certain data.

\section{Systems}

- Any system within an organization or webbased system.

- Set of nodes inside the blockchain network.

- Blockchain platform.

\section{Data}

- Set of Hashes saved in the blocks of the blockchain.

\section{Steps of creating records in $B C$}

1. The Issuer creates the electronic document (agreement, contract, etc.).

2. The issuer uploads the electronic document into $\mathrm{BC}$.

3. $\mathrm{BC}$ generates the hash for the E-document.

4. BC stores the hash in block.

\section{Steps of proving the Integrity of record}

1. The verifier uploads the E-document into $\mathrm{BC}$.

2. BC generates the Hash code for the Edocument.

3. BC checks the resulted hash by comparing the resulted hash with the stored hashes.

4. If the resulted hash equal one of the hashes stored in the blockchain, then 
the file exists, and we achieved the proof of Integrity.

Putting the pattern to use

This pattern can be used in the systems that contain unique and high-value records such as the registries of patents, academic certificates, and property registries.

Benefits

- Help protect and share authentic and integral information in a decentralized platform which is secured with encrypted codes.

- Track each transaction with a date stamp which ensures reliability and accountability.

- Improve the quality of services in different industries such as government.

- Save time and efforts of users by using one platform for inquiring the integrity data as a source of truth for different business parties.

\section{Pattern figure}

Figure 2 explains the process of checking integrity by using $\mathrm{BC}$ and without using BC.

\section{Demonstration}

Our contribution includes explains the concept of the pattern of integrity in blockchain and illustrates an example to describe it (evaluation section). By creating pattern of integrity, we contributed to finding the solution to the authentication problem. We found the integrity achieved by using the Hash algorithm in the process of creating and verifying the record. The Hash algorithm is used to achieve integrity for records. So, all the documents that registered in $\mathrm{BC}$ are authentic and have absolute evidence of when a document is uploaded. By achieving proof of integrity, we would be already achieved the proof of existence and proof of ownership for the land. Accordingly, the PoI pattern will guide organizations to implement a blockchain and resolve ambiguities related to how to benefit from its opportunities in achieving integrity.

\section{E. Evaluation and Results}

In this part, we will follow the PoI pattern to analysis the case of verification of certificates and then we will check how implementation part compatible with PoI pattern and the uses cases that we described previously in Table 1.

\section{1- Implementing PoI Pattern to Check Authentication of Academic Certificates}

Pattern Name: Proof of integrity for the academic certificates

\section{Context/ the problem}

Verification of certificates is a timeconsuming process as it may require days or weeks. Employers are concerned about the qualifications authentication and spend much time communicating with universities to verify the integrity of certificates and to ensure applicants held an impeccable qualification. Blockchain will provide transparency and simplify sharing the authenticated certificates with a variety of employers or any other parties [23], [24], [25].

\section{Solution}

Employers can prove the integrity of the academic certificate by using BC. BC provides a recognized secure source to store students' qualifications, accessible by a variety of institutions and universities. It provides a persistent public record, safeguarded against changes to the institution or loss of its private records ${ }^{[26]}$.

This pattern consists of the following components: 
Users

- Issuer (University)

- Recipient (Students)

- Verifier (Employers)

\section{Systems}

- The nodes of universities.

- Blockchain Platform

\section{Data}

- The certificates hashes
- Electronic certificate file

Steps of proving the authentication of certificates:

The process of checking the integrity of the certificate depends on checking the hash value of the certificate and compare the hash with the hashes stored in the blockchain as Fig. 3 displayed.
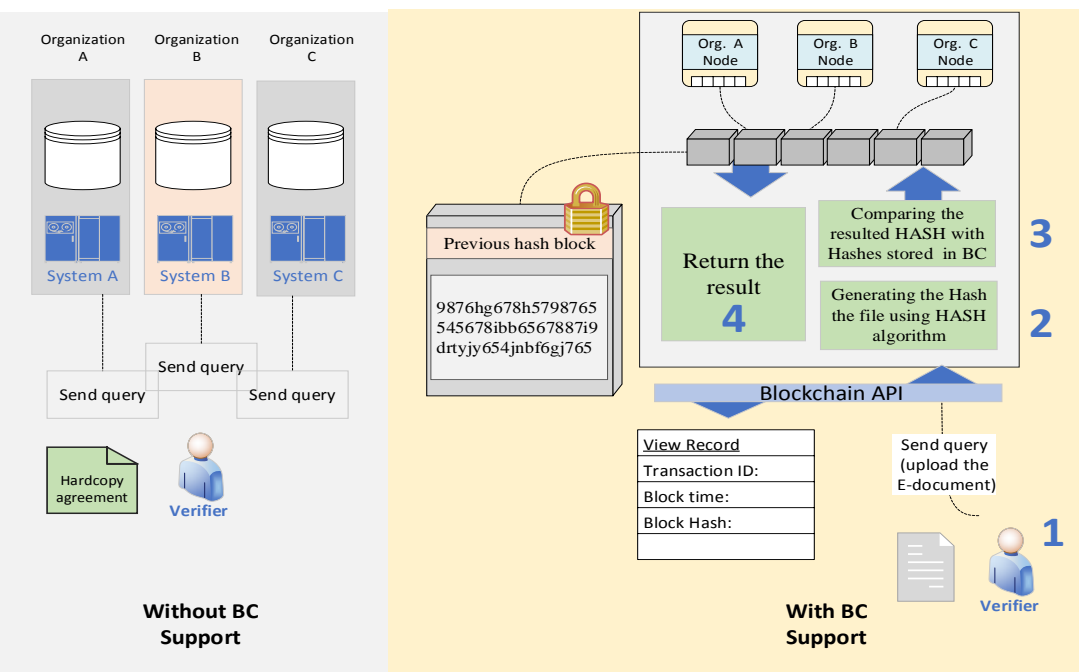

Fig. 2. The pattern of proof of integrity (PoI).

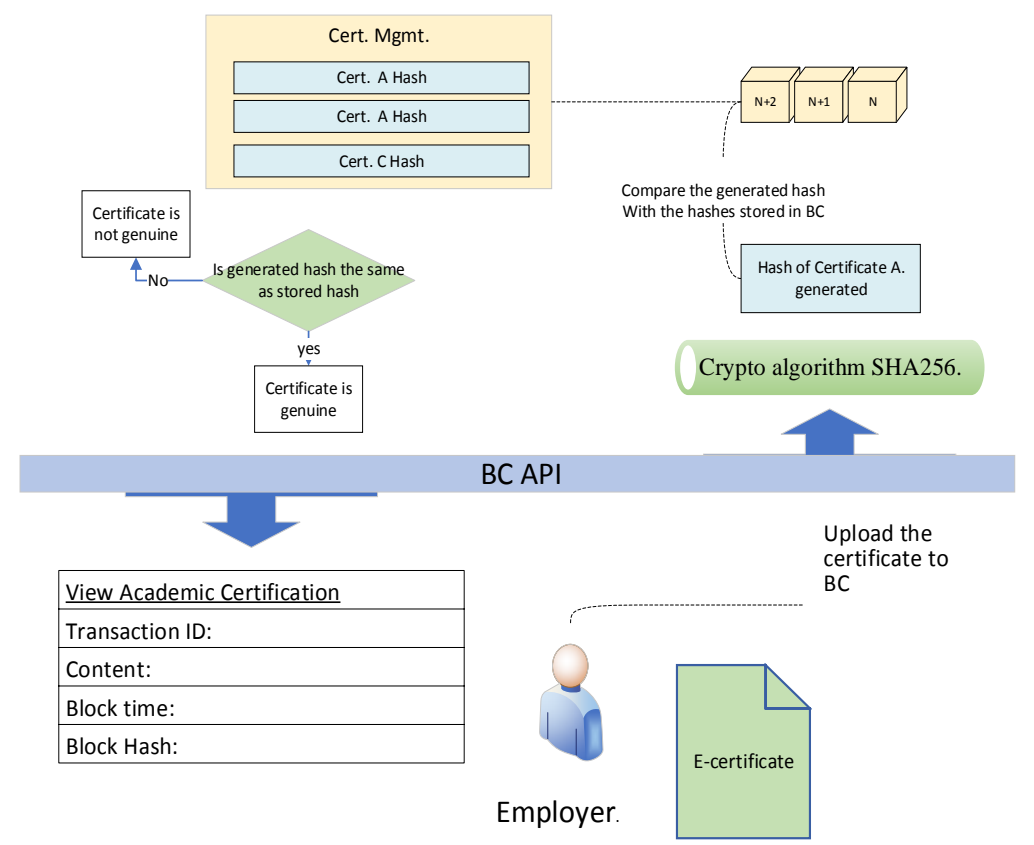

Fig. 3. Pattern PoI for certificates. 
- University issues a new electronic certificate for a student and uploads the file into $\mathrm{BC}$.

- BC hashes and stores the file of the certificate.

- To proof of integrity, the student or employer upload the document of the certificate into $\mathrm{BC}$ platform

- BC generates the hash for the document and then compares the generated hash value with hashes stored on the blockchain.

- If the generated hash match one of the hashes stored in blockchain then the certificate is authentic ${ }^{[24],[25]}$.

Benefits of using $\mathrm{BC}$ to authenticate the academic certificates:

- BC solves the current difficulties in validation and authentication process.

- BC can group all universities in one single platform.

- BC technology encourages employers to work with universities in a systematic way.

- BC helps save and share authentic and integral information as one source of truth.

- Saves time, cost and efforts [23], [24].

\section{Designing an Application to Evaluate PoI Pattern}

In this part, the focus is on the demonstration of how the implementation part is compatible with the purposed pattern PoI and the uses cases that we described previously.

\section{a. Application of Checking Authentication of Certificates}

To evaluate our method for accomplishing records integrity, we created an application to check the process of saving and retrieving the E-certificates in the blockchain.

\section{b. Designing the Application Structure}

The application composed of two parts the first, part of publishing and the second part of verifying as shown in Fig. 4. The details of the code as follows:

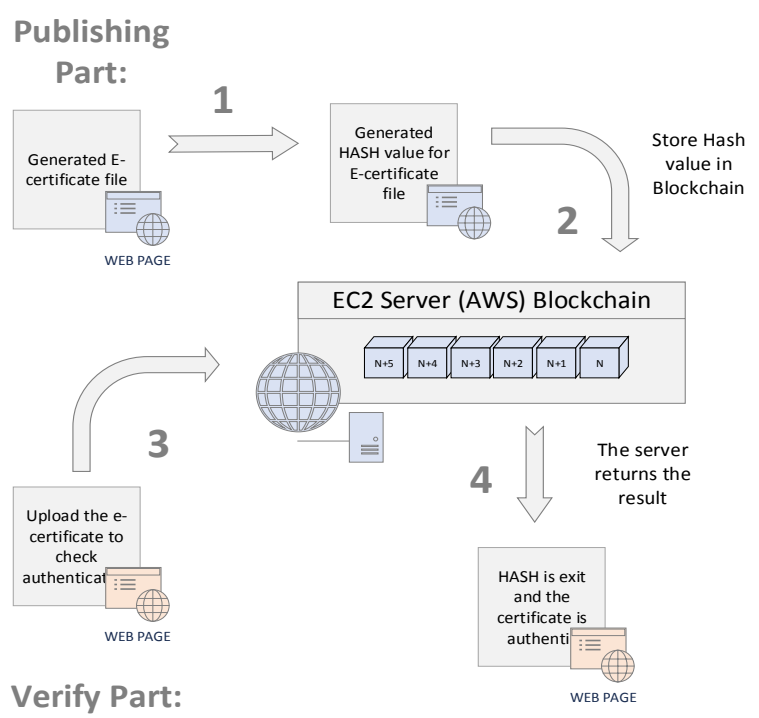

Fig. 4. The structure of $\mathrm{BC}$ application to check proof of integrity.

\section{Publishing Part}

This part is responsible for uploading the certificate file and then generating the Hash value of the file. After that, the hash stored into the blockchain network.

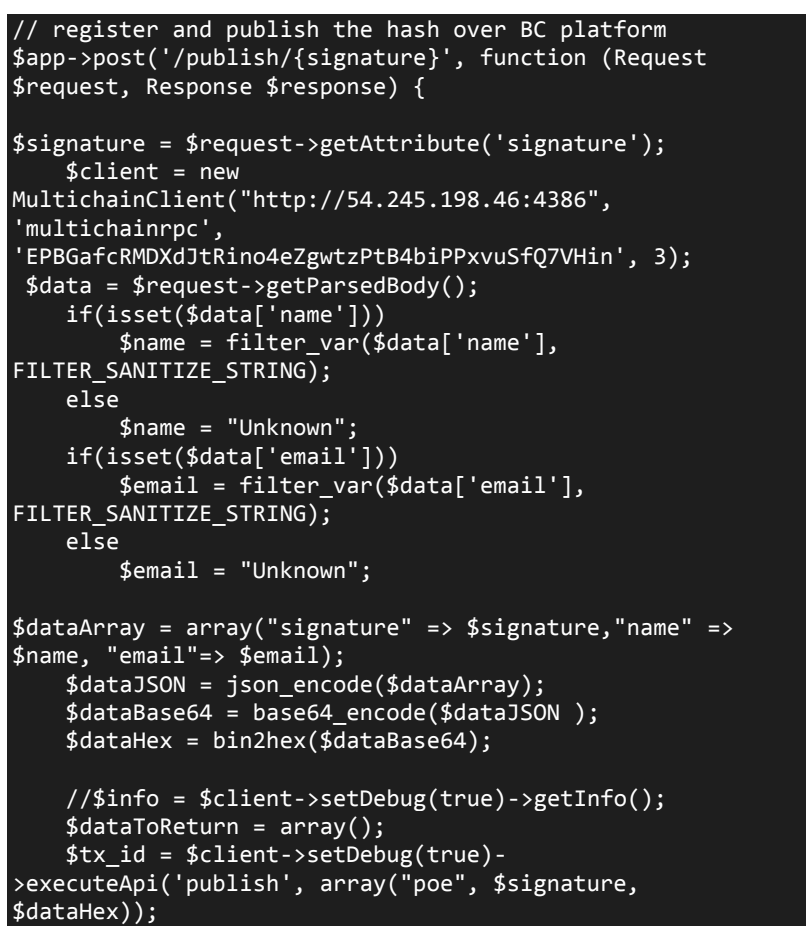




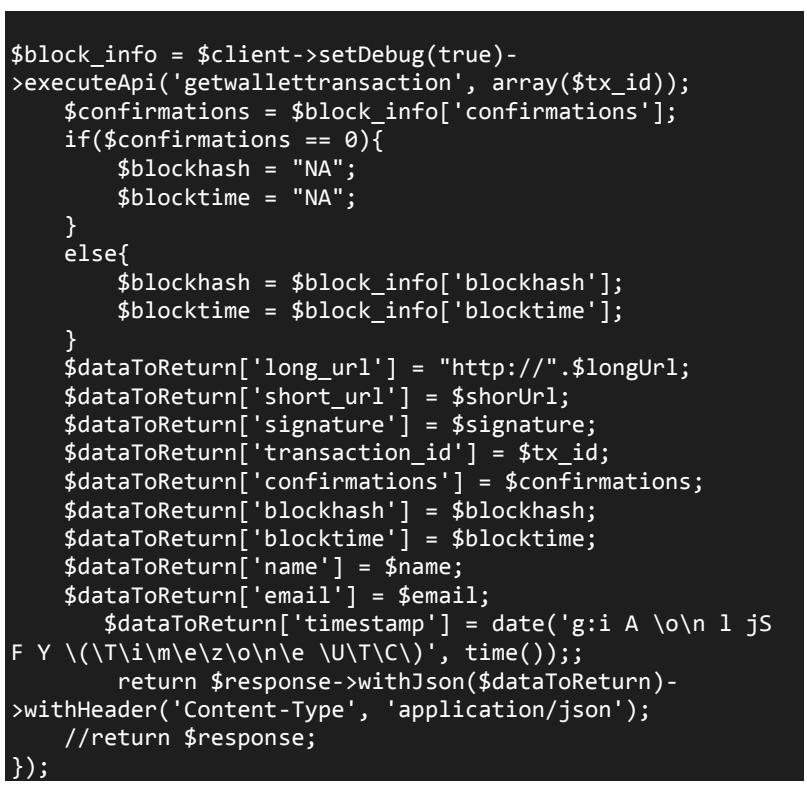

\section{Verifying Part}

Through the $\mathrm{BC}$ platform, the verifier uploads the file to check the integrity of the certificate, the server retrieves the Hash value of the file and send it to the blockchain (virtual server) to check whether the hash is existing or not. The server responds with details. If the hash is found, then we have already achieved the authentication of the certificate, if the hash does not retrieve, then the certificate is not authentic.

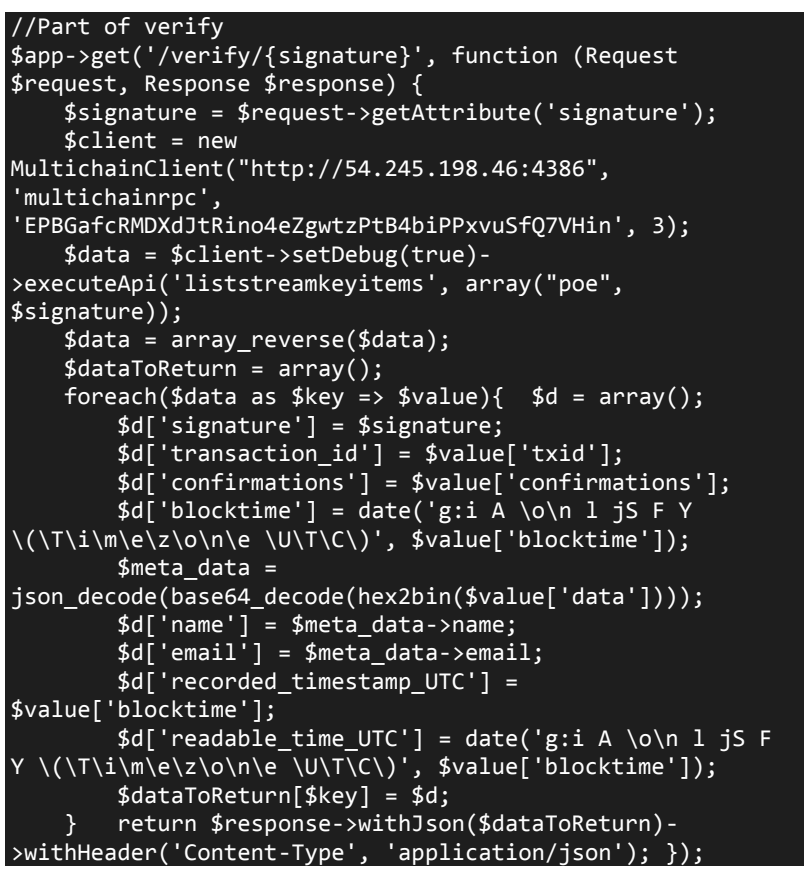

\section{c. Implementation Part}

To creating a blockchain application, we need at the beginning choosing an appropriate platform, and we chose multichain because its open platform used to create private blockchain for storing and retrieving records.

1- Uploading the document to the BC platform to generate the hash.

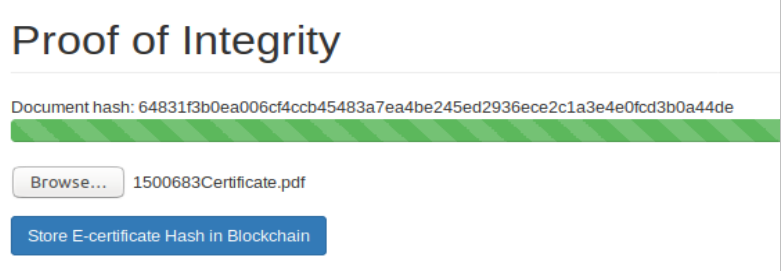

Fig. 5. Generating the Hash through API.

2- Creating a node over blockchain using multichain it is called: first Chain.

3. To display information of the created blockchain, we use getinfo function.

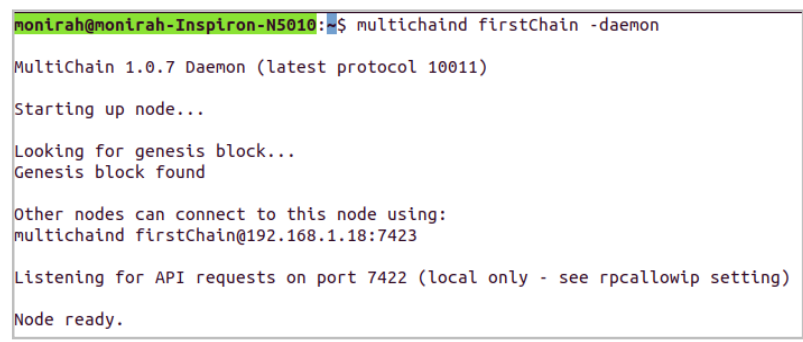

Fig. 6. The process of creating Node on Multichain platform.

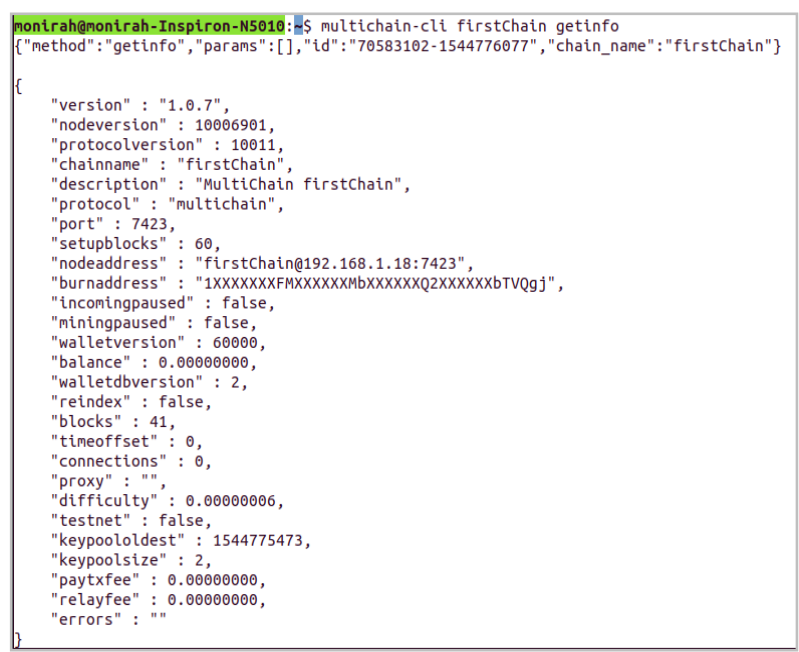

Fig. 7. Displaying the content of Node. 


\section{Linking AWS server with multichain.}

monirah@monirah-Inspiron-N5010: /. multichain/chain1\$ cat multichain. conf
rpcuser=multichainrpc rpcpassword=EPBGafCRMDXdJtRino4eZgwtzPtB4biPPXVuSfQ7VHin

Fig. 8. Username and password to connect Multichain with the server.

Sclient = Multichainclient ("Remote Server: client port", 'username', 'password', 3);

Sclient

MultichainClient ("http://<chainurl>:8000" , 'multichainrpc',

'EPBGafCRMDXdJtRino4eZgwtzPtB4bi PPXVuSfQ7 VHin', 3);

Port number to Connect the machine with the remote server, default TCP/IP port for incoming JSON-PRC API requests)

After we created a node in the blockchain, we need to create a stream. A stream is used for storage and retrieval hashes in the multichain platform. It contains the key value pair of information. We use the following command to create stream:

create stream streaml false

Then, we store data into this stream (the hash value of the e-certificate). After that, we will list all the items available in the stream by using this command which shows the key and data.

4. Creating a stream, it is called poe, which can be used for general data storage and retrieval. In this step, the hash of the file is generated and stored in Amazon block-chain server.

5. List the containing stream by using liststreamitems command to retrieve the contents of the stream.

The final step, we tested the authentication through the API.

By comparing the resulted hash in this figure and in the hash that generated on the first figure, we retrieved the same hash which equals: 64831f3b0ea006cf4ccb45483a7ea4be245ed29 $36 e c e 2 c l a 3 e 4 e 0 f c d 3 b 0 a 44 d e$

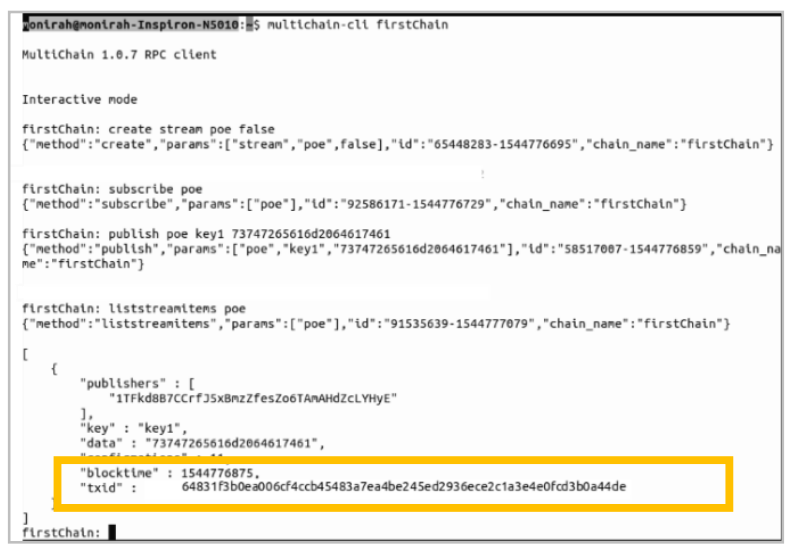

Fig. 9. Verifying process.

By reaching this result, we conclude that the certificate is authentic, and we evaluated our proposed pattern.

\section{Conclusion}

This research showed how the PoI pattern represented the role of $\mathrm{BC}$ to achieve integrity. We observed that integrity had been achieved by using the hash algorithm. As a result, we reached to create PoI pattern which works based on the concept of the Hash algorithm. Accordingly, the PoI pattern will help to guide business that wants to achieve integrity in their records. Moreover, it will contribute guiding organizations to move smoothly to a blockchain which would resolve ambiguities related to how to use blockchain and how to benefit from its opportunities. To check PoI pattern compatibility with other cases, we evaluated the PoI pattern by implementing it to a blockchain application to show how integrity is achieved in the process of saving and retrieving the records.

Reflecting, we concluded that the PoI pattern had demonstrated its suitability to many examples. Moreover, PoI pattern can be used as a model to find solutions for problems of authentication in different areas. 


\section{Acknowledgment}

I would like to express my appreciation to myself and to Dr. Kawther who supervised me to complete this paper.

\section{References}

[1] Institute, N. R. "Survey on Blockchain Technologies and Related Services," Japan's Ministry of Economy, Trade and Industry (METI), Japan, 2016.

[2] Hancock, E. V. Matthew, "Distributed Ledger Technology: beyond block chain," A report by the UK Government Chief Scientific Adviser, 2015.

[3] Seebacher, R. S. Stefan, "Blockchain Technology as an Enabler of Service Systems: A Structured Literature Review," (C) Springer International Publishing AG 2017, pp. 12-23, 2017.

[4] Jan Mendlin, I. W. W. v. d. A. J. v. B. C. C. F. D. S. D. C. D. C. M. D. S. D. A. G. L. G.-B. G. G. R. H., "Blockchains for Business Process Management Challenges and Opportunities," ACM Transactions on Management Information Systems, 2017.

[5] Sadouskaya, K., "Adoption of Blockchain Technology in Supply Chain and Logistics," Kaakkois- Suomen Ammattikorkeakouluoy, 2017.

[6] Kakavand, i. c. w. C. B. C. Hossein and De Sevres, Nicolette Kost, "The Blockchain Revolution: An Analysis of Regulation and Technology Related to Distributed Ledger Technologies," luthersystems, 2016.

[7] Y. H. T. J. Watson Research Center, "Blockchain: Distributed Event-based Processing in a Data-Centric World: Extended Abstract," 2017.

[8] T. T. A. D. J. W. G. C. R. L. C. O.-L. Tan, "BLOCKBENCH: A Framework for Analyzing Private Blockchains," pp. 14-19, 2017.

[9] Fan Zhang, E. C. K. C. A. J. E. S., "Town Crier: An Authenticated Data Feed for Smart Contracts," pp. 24$28,2016$.

[10] Dulak, J. T., "Business Process," 2014.

[11] Ken Peffers, T. T. M. A. R. S. C., "A Design Science Research Methodology for Information Systems Research," Journal of Management Information Systems, vol. 24, 2008.

[12] Xiwei Xu, L. Z. C. Q. L. C., "A Pattern Collection for Blockchain-based Applications," Association for Computing Machinery, 2018.
[13] Swan, M., Blockchain Blueprint for a New Economy, Tim McGovern, 2016.

[14] Roman Beck, M. A. M. R. J. B. T., "Blockchain Technology in Business and Information Systems Research," Business \& Information Systems Engineering, vol. 59, no. 6, 2017.

[15] V. M. K. B. Babu Pillai, "Challenges in Designing a Blockchain Platform," 2017.

[16] Lemieux, V. L., "Trusting records: Is Blockchain technology the answer? " Records Management Journal, 2017.

[17] Šalehar, D., "Pattern Based Evaluation of Blockchain Technology as a catalyst for Business Model Innovation," 2017. [Online].

[18] Okupski, K., "Using Bitcoin for an Anti-Censorship Tool," Department of Mathematics and Computer Science, pp. 2-96, 2016.

[19] Dell'Aversana, R., "Verification of Data Aware Business Process Models: A Methodological Survey of Research Results and Challenges," Springer International Publishing Switzerland, 2015.

[20] Zhao, L. M. b. J. A. c. P. V. Liping, "A pattern language for designing e-business architecture," The Journal of Systems and Software, 2008.

[21] Adams, S. K. G. B., Jonathan Pattern for E-business a Strategy for Reuse, IBM Press, 2009.

[22] Drescher, D., "Using the Blockchain A Tool with Thousands of Applications," in Blockchain Basics, Springer, 2017.

[23] Gräther, S. K. R. R. J. S., Wolfgang "Blockchain for Education: Lifelong Learning Passport," Proceedings of the 1st ERCIM Blockchain Workshop, 2018.

[24] Grech, A. and Camilleri, A. F., "Blockchain in Education," Publications Office of the European Union 2017.

[25] Domingue, M. S. a. J., "The Blockchain and Kudos: A Distributed System for Educational Record, Reputation and Reward," EC-TEL, 2016.

[26] O. G. a. O. S. Saleh, "Graduation Certificate Verification Model via Utilization of the Blockchain Technology," Journal of Telecommunication, Electronic and Computer Engineering, no. 10, 2017. 


\title{
نمط إثبات النزاهة للنطبيقات الإلكترونية باستخدام تقنية البلوكتثين
}

\author{
منيره دخيل الله المالكي و كوثز عبدالإله صعيدي \\ قسم نظم المعلومات، كلية الحاسبات وتقنية المعلومات، جامعة الملك عبدالعزبز، جدة، المدلكة العربية السعودية \\ malmalki0408@stu.kau.edu.sa
}

المستخلص. سلسلة الكتل (البلوكتشين) هي تقنية جديدة تحظى باهتمام كبير في العديد من

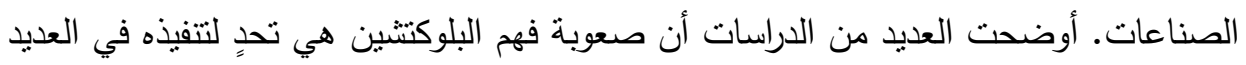
من الأعمال. ونتيجة لذلك، فإن إجراء الدراسات في تصميم تطبيقات البلوكتشين هو خطوة مطلوبة للمساهمة في تبسيط تطبيقه واستكثاف تأثيره على سلامة وكفاءة وإنتاجية المعاملات في الأعمال. وفقًا لذلك، ركز هذا البحث على دراسة دور البلوكتشين في تحقيق النزاهة ومعالجة نقص المصادقة الذي لا يزال يمثل تحديًا في العديد من مجالات العمل. يعتبر تحقيق النزاهة

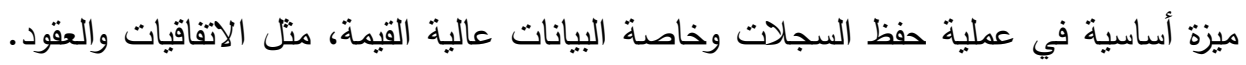
بناءً على مراجعة الأدبيات، فإن إحدى الطرق لمعالجة المشكلة والمساهمة في فهم الحل هي إنشاء أنماط. في هندسة البرمجيات يساعد تصميم النمط في فهم المشكلة التي تحدث مرارًا وتكرارًا ويصف الحل الخاص بها. يكمن الدافع وراء هذا البحث في تقديم مساهمة في مجال نهج تصميم الأنماط لتطبيقات البلوكتشين من أجل حل مشكلة نقص المصادقة في عملية تخزين ، والذي يمكن Pol|لبيانات واسترجاعها. خلصنا إلى نمط عام أسميناه نمط إنبات النزاهة

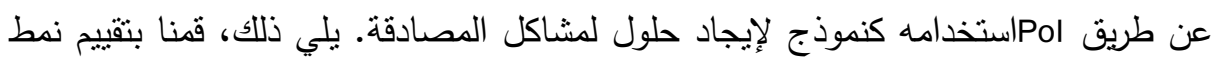

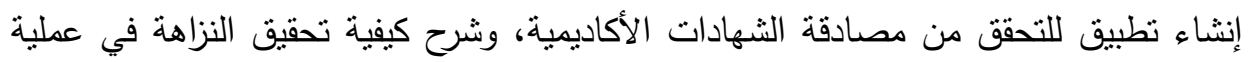
• توصلنا إلى أن Pol تخزين السجلات، واستعادتها، والتحقق من مدى نوافق التطبيق مع نمط

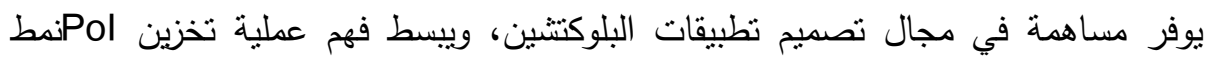
واسترجاع البيانات الموجودة على البلوكتشين، والتي ستساعد في حل المشكلات المتعلقة

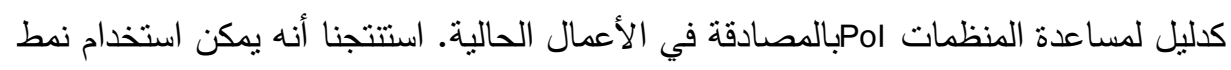
على اتخاذ القرار المناسب عند تتفيذ البلوكتشين ومساعدتهم على الانتقال بسلاسة إلى الى البلوكتشين.

الكلمات الدفتاحية: البلوكتشين، نمط، النز اهة، المصادقة، إثبات النزاهة. 
